\title{
PERBEDAAN ANTARA INTERVENSI SHORT WAVE DIATHERMY DENGAN CRYOTHERAPY TERHADAP SKALA FUNGSI PENDERITA OSTEOARTHRITIS LUTUT
}

\author{
Elly Mayangsari ${ }^{\star \star 凶}$, Rahmad $^{* *}$, Nately Diana Binti Razali***
}

\begin{abstract}
Abstrak
Osteoarthritis $(\mathrm{OA})$ adalah gangguan kronis pada sendi synovial, yaitu terjadi pelunakan yang progresif dan kerusakan pada tulang rawan sendi yang mengakibatkan nyeri dan gangguan fungsi. OA lutut simtomatik terjadi pada 10\% laki-laki dan 13\% wanita yang berusia 60 tahun ke atas. Tujuan dari penelitian ini adalah untuk melihat perbedaan antara intervensi short wave diathermy (SWD) dan cryotherapy terhadap skala fungsi pasien OA lutut dengan munggunakan VAS, WOMAC, dan 10MWT. Metode penelitian ini adalah experimental dengan consecutive sampling. Pasien diukur tingkat fungsional sebelum dan sesudah satu kali terapi SWD (15 pasien) atau cryotherapy (15 pasien) menggunakan skala VAS, WOMAC dan 10MWT. Hasil penelitian pada pasien yang menerima SWD, rata-rata nilai VAS menurun dari 4,400 menjadi 2,467 ( $p=$ $0,003)$, rata-rata nilai WOMAC menurun dari 24,600 menjadi $15,200(p=0,004)$ dan rata-rata nilai 10MWT menurun dari 8,361 menjadi 7,891 $(p=0,789)$. Pada pasien yang menerima cryotherapy, rata-rata nilai VAS menurun dari 5,467 menjadi $2,867(p=0,003)$, rata-rata nilai WOMAC menurun dari 35,000 menjadi 23,867 $(p=0,003)$ dan rata-rata nilai 10MWT meningkat dari 8,907 menjadi 8,946 namun tidak bermakna $(p=$ $0,691)$. Pada satu kali terapi SWD dan cryotherapy mampu menurunkan VAS dan WOMAC secara signifikan, namun belum cukup untuk memperbaiki 10MWT. Tetapi pada perbandingan antara kedua kelompok SWD dengan cryotherapy tidak terdapat berbedaan yang bermakna. Kesimpulannya, terdapat perbedaan skala fungsi pasien OA lutut dari VAS dan WOMAC pada intervensi SWD atau cryotherapy. Pada penilaian 10MWT tidak terdapat perbedaan pada intervensi SWD atau cryotherapy.
\end{abstract}

Kata kunci: cryotherapy, osteoarthritis, short wave diathermy.

\section{THE DIFFERENCE BETWEEN SHORT WAVE DIATHERMY INTERVENTIONS WITH CRYOTHERAPY ON THE FUNCTIONING SCALE OF KNEE OSTEOARTHRITIS PATIENTS}

\begin{abstract}
Osteoarthritis $(\mathrm{OA})$ is a chronic disease on the synovial joint where the cartilage goes through a progressive softening and damage that causes pain and dysfunction of the knee. Symptomatic knee OA is present on $10 \%$ of men and $13 \%$ women at the age of 60 years old and above. The purpose of this research was to study the differences between SWD and cryotherapy intervention on the functional scale of patients with knee OA using VAS, WOMAC, and 10MWT. The method used in this research is an experimental design method with consecutive sampling. The functional scale of each patient was measured pre and post SWD (15 patients) or pre and post cryotherapy SWD (15 patients) using VAS, WOMAC, and 10MWT. The result from the experiment showed that the average value of VAS in patients that received SWD decreased from 4.000 to $2.467(p=0.003)$, while in WOMAC decreased from 24.600 to $15.200(p=0.004)$ and in 10MWT decreased from 8.361 to $7.891(p=0.789)$. The average value of VAS in patients that received cryotherapy decreased from 5.467 to 2.867 ( $p=0.003$ ), while in WOMAC decreased from 35.000 to 23.867 $(p=0.003)$ and in 10MWT increased from 8.907 to $8.946(p=0.691)$. Single session therapy of SWD or cryotherapy could decrease VAS and WOMAC significantly, but it was not sufficient to decrease the value of 10MWT. The comparison between both groups, SWD and cryotherapy did not show a meaningful differrence. In conclusion, there are differences in the functional scale of knee OA patients from VAS and WOMAC in SWD or cryotherapy intervention. At the 10MWT assessment, there was no difference in SWD or cryotherapy intervention.
\end{abstract}

Keywords: cryotherapy, osteoarthritis, short wave diathermy.

${ }^{*}$ Departemen Farmakologi, Fakultas Kedokteran, Universitas Brawijaya ${ }^{* *}$ Departemen Rehabilitasi Medik, Fakultas Kedokteran, Universitas Brawijaya

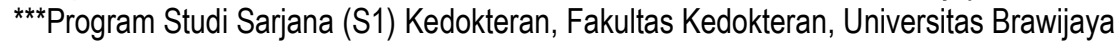

E-mail: mayangga1605@gmail.com 


\section{Pendahuluan}

Osteoartritis (OA) adalah gangguan kronis pada sendi sinovial yaitu terjadi pelunakan yang progresif dan kerusakan pada tulang rawan sendi diikuti oleh penumbuhan tulang rawan dan tulang yang baru di sendi (osteophytes), pembentukan kista dan sklerosis di dalam tulang subchondral dan sinovitis yang ringan dan fibrosis kapsular. OA merupakan ganguan pada sendi yang tidak simetris dan sering terdapat hanya pada satu bagian daripada sendi. ${ }^{1}$

Penderita OA di Amerika adalah sekitar 27 juta. $^{2}$ Bedasarkan penelitian yang telah dilakukan oleh Zhang dan Jordan (2010), OA lutut simtomatik sering terjadi pada 10\% lakilaki dan $13 \%$ wanita yang berusia 60 tahun ke atas. ${ }^{3,4}$ Prevalensi OA lutut di Indonesia adalah sebanyak $15,5 \%$ pada laki-laki dan $12,7 \%$ pada wanita. Prevalensi OA lutut pada usia 40-60 tahun mencapai $30 \%$ dan $65 \%$ pada usia 61 ke atas. OA sering terdapat pada sendi penopang berat badan seperti lutut, panggul, dan vertebra. Namun, OA lutut yang paling sering ditemukan dan merupakan penyebab utama disabilitas di dunia, terutama karena nyeri dan gejala utama dari penyakit ini. ${ }^{4}$

Nyeri adalah tanda simtomatis yang paling sering dirasakan oleh pasien $O A$ dan gejala ini mendorong individu untuk mencari bantuan medis. ${ }^{4}$ Gejala seperti nyeri, kaku dan krepitasi pada pasien OA menyebabkan keterbatasan dalam pergerakan. ${ }^{4}$ Ketidakstabilan sendi menyebabkan penderita $O A$ kehilangan fungsi dan terjadi limitasi dalam aktivitas sehari hari karena nyeri dan kekakuan. ${ }^{5}$ OA lutut juga menyebabkan penurunan range of motion pada pasien dan secara tidak lansung menurunkan kadar fungsional lutut pada pasien OA seperti kesulitan melakukan pekerjaan sehari-hari dan kesulitan untuk berjalan 6

Berdasarkan National Health Service (NHS) di antara terapi utama yang diberikan kepada pasien $\mathrm{OA}$ adalah merubah cara hidup, pemberian obat dan terapi suportif. Rehabilitasi merupakan salah satu terapi suportif yang sering digunakan untuk membantu mengurangi kekakuan, bengkak, dan nyeri pada sendi lutut pasien OA. Terapi short wave diathermy (SWD) dan cryotherapy adalah salah satu terapi yang digunakan untuk mengurangkan rasa nyeri dan secara tidak lansung dapat meningkatkan fungsi lutut dan memperbaiki aktivitas harian pasien. ${ }^{7}$

Sebuah penelitian tentang efek cryotherapy terhadap nyeri, fungsional lutut, dan kualitas hidup pada individu dengan OA lutut dengan kelompok kontrol yang menerima kantung pasir, terapi diberikan selama 4 hari. Hasil dari penelitian ini mendapatkan bahwa pemberian cryotherapy jangka pendek dibandingkan kelompok kontrol yang menerima kantung pasir tidak lebih efektif untuk menurunkan nyeri fungsional lutut dan meningkatkan kualitas hidup pasien, karena kedua kelompok menunjukkan penurunan pada visual analogue scale (VAS), Western Ontario and McMaster Universities Osteoarthritis (WOMAC), dan timed up and go (TUG). Nilai VAS pada kelompok yang menerima cryotherapy menurun dari 6,8 menjadi 1,6 dan VAS pada kelompok kontrol menurun dari 6,8 menjadi 2,3, WOMAC pada kelompok yang menerima cryotherapy menurun dari 44 menjadi 12 dan WOMAC pada kelompok kontrol menurun dari 41 menjadi 15, TUG pada kelompok yang menerima cryotherapy menurun dari 8,6 menjadi 7,5 dan TUG pada kelompok yang kontrol menurun dari 9,0 menjadi $8,3.8$

Selain itu, penelitian tentang efektivitas SWD terhadap nyeri pada pasien OA dengan membandingan satu kelompok menerima terapi SWD dan latihan fisik dan kelompok kontrol hanya diberikan terapi fisik, terapi diberikan 5 kali dalam 1 minggu selama 3 minggu. Setelah 1 bulan, nilai VAS pada kelompok yang menerima SWD turun dari 78,5 menjadi 49,8 dan VAS pada kelompok kontrol menurun dari 80 menjadi 54,0. Nilai WOMAC 
dari 14,0 menjadi 10,0 dan WOMAC pada kelompok kontrol turun dari 13,7 menjadi 10,7. Nilai Nottingham Health Profile (NHP) mobility pada kelompok yang menerima SWD turun dari 42 menjadi 33 dan pada kelompok kontrol turun dari 47,5 menjadi 36,5.9

Berdasarkan uraian di atas, diketahui bahwa pada kelompok yang diberikan terapi cryotherapy dan SWD menunjukkan perbedaan yang lebih banyak dibandingkan dengan kelompok kontrol. Maka, peneliti ingin membandingkan antara terapi SWD dengan cryotherapy, manakah yang lebih efektif dalam meningkatkan fungsi lutut pasien $O A$ setelah terapi diberikan. Selain itu, dalam pelayanan sehari-hari, pasien mengharapkan terdapat manfaat dan efek segera setelah pemberian terapi.

\section{Bahan dan Metode}

\section{Rancangan Penelitian}

Penelitian ini berjenis eksperimental dengan consecutive sampling pada pasien OA lutut di Instalasi Rehabilitiasi Medik RSUD Dr. Saiful Anwar Malang (RSSA), Rumah Sakit Umum Universitas Muhammadiyah Malang (RSUMM), dan Klinik Husada Asih, Malang. Populasi penelitian adalah pasien OA lutut yang bersedia untuk mengikuti penelititan ini yang memenuhi kriteria inklusi dan eksklusi. Pada penelitian ini, sampel yang digunakan adalah sebanyak 30 pasien yang akan dibagi menjadi 2 kelompok yaitu pasien yang menerima terapi SWD dan pasien yang menerima terapi cryotherapy. Setiap pasien akan diukur visual analogue scale (VAS), Western Ontario and McMaster Universities Osteoarthritis (WOMAC) dan 10 meter walk test (10MWT) sebelum dan sesudah diberikan satu kali intervensi.

\section{Sampel Penelitian}

Pada penelitian ini terdapat 2 perlakuan yaitu short wave diathermy dan cryotherapy. Untuk 2 perlakuan, diperlukan pengulangan paling sedikit sebanyak 15 pasien untuk tiap perlakuan sehingga total sampel pasien yang diperlukan dalam penelitian ini adalah 30 pasien.

\section{Kriteria Inklusi dan Eksklusi}

Kriteria inklusi dalam penelitian ini yaitu: (1). Diagnosis osteoarthritis lutut dengan semua grade 1, 2, 3, dan 4, (2). Osteoarthritis unilateral dan bilateral, (3). Pasien yang mendapat terapi farmakologi dan yang tidak mendapat terapi farmakologi, dan (4). Usia pasien 40 tahun ke atas. Sedangkan kriteria eksklusinya yaitu: (1). Terdapat transcutaneous neural stimulator seperti cardiac pacemaker, (2). Mempunyai implant besi dan keganasan pada area lutut, (3). Alergi kepada electrode atau bahan kontak seperti gel, (4) Penyakit dermatologi akut atau luka terbuka (5). Jaringan parut yang luas, (6). Menjalani terapi deep $\mathrm{x}$-ray atau radiasi pengion lainnya dalam waktu 6 bulan terakhir pada lutut, dan (7). Alergi dingin.

\section{Bahan dan Alat Penelitian}

Bahan dan alat yang akan digunakan dalam penelitian ini adalah alat short wave diathermy (Physiomed, BTL), alat cryotherapy (Zimmer, MECOTEC), visual analog scale (VAS), kuesioner WOMAC index, dan 10meter walk test (10MWT).

\section{Analisis statistik}

Hasil pengukuran fungsional lutut akan dianalisis secara statisttik dengan menggunakan Wilcoxon test untuk membandingkan kadar fungsional lutut sebelum dan sesudah terapi. Langkah-langkah uj hipotesis komparatif menggunakan Mann Whitney dengan nilai signifikasi $p=0,05$.

\section{Hasil}

Hasil pengujian sebelum dan sesudah terapi SWD dapat diketahui pada Gambar 1 
bahwa terdapat perbedaan nilai VAS yang signifikan sebelum dan sesudah diberikan SWD $(p=0,003)$. Diketahui nilai rata-rata VAS sesudah diberikan SWD bernilai lebih rendah $(2,467)$ dari rata-rata VAS sebelum diberikan SWD (4,4). Pada Gambar 1 juga dapat dilihat perbedaan nilai WOMAC yang signifikan sebelum dan sesudah diberikan terapi SWD $(p=0,004)$. Diketahui rata-rata nilai WOMAC sesudah diberikan SWD bernilai lebih rendah $(15,2)$ dari rata-rata nilai WOMAC sebelum diberikan SWD $(24,6)$. Akan tetapi, hasil menunjukkan nilai 10MWT yang berbeda tidak signifikan sebelum dan sesudah diberikan terapi SWD ( $p=0,798)$ (Gambar 1). Hal ini ditunjukkan oleh rata-rata nilai 10MWT sesudah diberikan SWD bernilai lebih rendah $(7,891)$ dari rata-rata 10MWT sebelum diberikan SWD $(8,361)$.

Pada Gambar 2 ditampilkan hasil terapi cryotherapy berdasarkan nilai VAS, WOMAC, dan 10MWT. Hasil menunjukkan perbedaan nilai VAS yang signifikan sebelum dan sesudah diberikan terapi cryotherapy $(p=$ $0,003)$. Hal ini ditunjukkan oleh rata-rata nilai VAS sesudah diberikan cryotherapy bernilai lebih rendah $(2,867)$ dari rata-rata VAS sebelum diberikan cryotherapy $(5,467)$. Selain itu, didapatkan perbedaan nilai WOMAC yang signifikan sebelum dan sesudah diberikan cryotherapy $(p=0,003)$. Ditinjau dari nilai rata -rata WOMAC sesudah diberikan terapi cryotherapy bernilai lebih rendah $(23,867)$ dari rata-rata WOMAC sebelum diberikan cryotherapy (35).

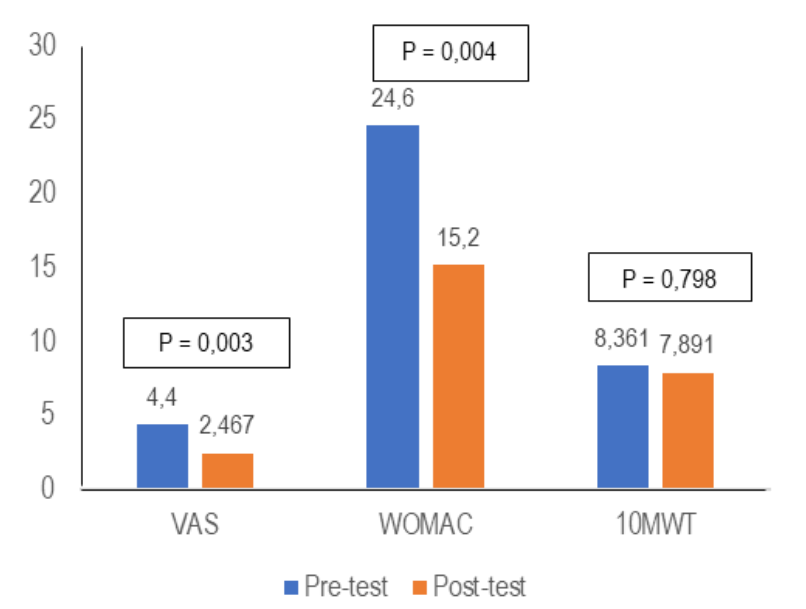

Gambar 1. Perbedaan nilai VAS, WOMAC dan 10MWT sebelum dan sesudah terapi SWD

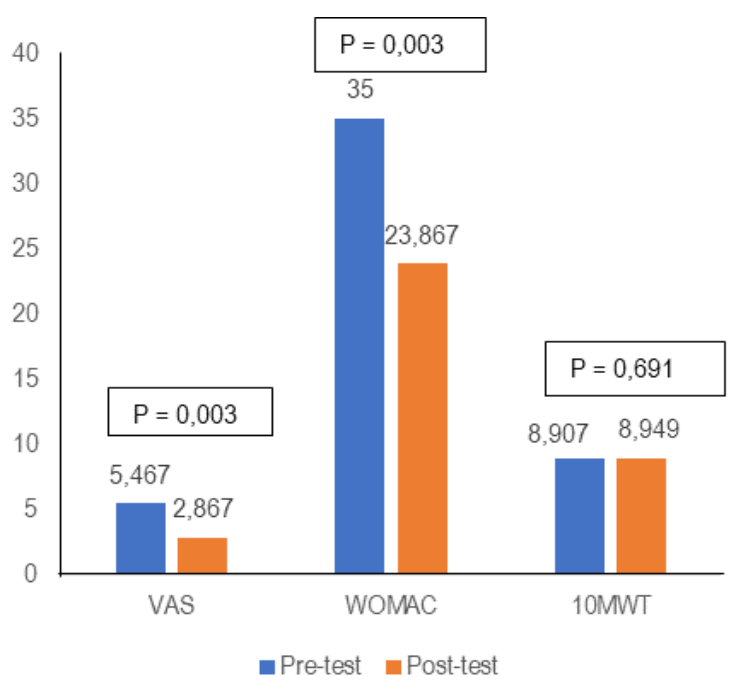

Gambar 2. Perbedaan nilai VAS, WOMAC dan 10MWT sebelum dan sesudah terapi cryotherapy. 
Pada Gambar 2, juga dapat dilihat adanya perbedaan 10MWT yang tidak signifikan sebelum dan sesudah diberikan terapi cryotherapy $(0,691)$. Hal ini dapat diketahui dari rata-rata nilai 10MWT sesudah diberikan cryotherapy bernilai lebih tinggi $(8,949)$ dari rata-rata 10MWT sebelum diberikan cryotherapy $(8,907)$.

\section{Pembahasan}

Pada penelitian ini diketahui adanya penurunan nilai VAS dan WOMAC. Hal ini menunjukkan bahwa terapi SWD mampu menurunkan nyeri dan meningkatkan fungsional lutut. Terapi SWD digunakan untuk mengurangi kekakuan, mengurangi spasme otot, mengurangi nyeri, menstimulasi respons antiinflamasi dan menstimulasi pemulihan jaringan ikat. ${ }^{9}$ Pada systematic review yang telah dilakukan oleh Jorge et al (2017), tentang pengaruh deep heating terhadap $\mathrm{OA}$ yang menyimpulkan bahwa agen pemanasan fisik seperti ultrasound, SWD dan microwave diathermy bermanfaat dalam mengurangi nyeri pada subjek dengan beberapa tingkat keparahan $\mathrm{OA}$ terutama dalam jangka waktu yang lama. ${ }^{10}$ Selain itu, pada systematic review pada efektivitas SWD pada pasien OA lutut yang telah dilakukan oleh Wang et al (2016) disimpulkan bahwa SWD mampu mengurangkan rasa nyeri pada subjek OA lutut. ${ }^{11}$

Selain itu, penurunan nilai VAS dan WOMAC ini menunjukkan bahwa terapi cryotherapy bisa menurunkan eksitasi pada ujung saraf bebas pada serabut saraf perifer sehingga menurunkan kecepatan konduksi saraf dan memberikan efek analgesik. ${ }^{12}$ Hasil penelitian ini sejalan dengan hasil penelitian Chrusciák (2016), bahwa pada pengujian whole body cryotherapy pada subjek $\mathrm{OA}$ didapatkan nilai rata-rata VAS sebelum diberikan terapi adalah 5,1 dan menurun menjadi 2,6 setelah diberikan 10 sesi whole body cryotherapy dan menyimpulkan bahwa whole body cryotherapy dapat menurunkan frekuensi dan tingkat persepsi nyeri pada subjek OA. ${ }^{13}$ Berdasarkan Dantas et al (2017), ditemukan efek cepat dari terapi cryotherapy terhadap nyeri, quality of life dan status fungsional pada penderita OA lutut. Terapi cryotherapy juga mampu menurunkan nyeri pada subjek OA lutut dan merupakan terapi non farmakologi dan terapi konservatif untuk subjek OA lutut. ${ }^{14}$

Namun pada 10MWT subjek yang menerima terapi SWD tidak menunjukkan perubahan yang signifikan. Nilai 10MWT menurun dari rata-rata 8,361 menjadi 7,891 dengan nilai $p=0,0798$. Pada 10MWT subjek yang menerima terapi cryotherapy juga tidak menunjukkan perubahan yang signifikan. Nilai 10MWT meningkat dari rata-rata 8,91 menjadi 8,95 dengan nilai $p=0,691$.

Perbedaan antara terapi SWD dan cryotherapy berdasarkan VAS dan WOMAC menunjukkan perbedaan $(p=0,003)$, sedangkan berdasarkan 10MWT tidak menunjukkan perbedaan yang signifikan $(p=0,798)$ karena SWD dan cryotherapy keduanya menunjukkan perbaikan pada VAS dan WOMAC, namun keduanya tidak menunjukkan perbedaan yang signifikan $(p=0,691)$ pada 10MWT. Menurut Adegoke et al (2004), bahwa tidak ada perbedaan yang signifikan antara terapi es dan SWD pada subjek OA lutut dan menyimpulkan bahwa pemberian es dan SWD pada subjek OA lutut dapat meningkatkan ROM dan fungsional subjek ${ }^{15}$.

\section{Kesimpulan}

Penelitian ini menyimpulkan terdapat perbedaan skala fungsi pasien $O A$ lutut dari VAS dan WOMAC pada satu kali intervensi SWD atau cryotherapy. Pada penilaian 10MWT tidak terdapat perbedaan pada satu kali intervensi SWD atau cryotherapy. 


\section{Daftar Pustaka}

1. Solomon $L$, Warwick $D$, and Nayagam $S$. Apley's System of Orthopedics and Fractures. 9th Edition. London: Hodder Education. 2010. Pp. 85-87.

2. Lawrence RC, Felson DT, Helmick CG, Arnold LM, Choi H, Deyo RA et al. Estimate of Prevalence of Arthritis and Other Rheumatic Conditions in the United States. Part II Arthritis and Rheumatism. 2008; 58(1):26-35. http://doi.org/10.1002/ art.23176.

3. Zhang $Y$ and Jordan JM. Epidemiology of Osteoarthritis. Clinics in Geriatric Medicine. 2010; 26(3):355-369. http:// doi.org/10.1016/j.cger.2010.03.001.

4. Neogi T. The Epidemiology and Impact of Pain in Osteoarthritis. Osteoarthritis and Cartilage/OARS, Osteoarthritis Research Society. 2013; 21(9):1145-1153. http:// doi.org/10.1016/j.joca.2013.03.018.

5. Sinusas K. Osteoarthritis: Diagnosis and Treatment. American Academy of Family Physician. 2012; 85(1):49-56.

6. Lespasio MJ, Piuzzi NS, Husni ME, Muschler GF, Guarino A, and Mont MA. Knee Osteoarthritis: a Primer. The Permanente Journal. 2017; 21:16-183. http:/l doi.org/10.7812/TPP/16-183.

7. NHS. Treatment osteoarthritis. (Online). 2016. Available from: https://www.nhs.uk/ conditions/osteoarthritis/treatment/.

[Diakses 25 Agustus 2018].

8. Dantas LO, Breda CC, da Silva Serrao PRM, Aburquerque-Sendín $F$, Serafim Jorge AE, Cunha JE, Salvini, TF. ShortTerm Cryotherapy Did Not Substantially Reduce Pain and Had Unclear Effects on Physical Function and Quality of Life in People with Knee Osteoarthritis: A Randomised Trial. Journal of Physiotherapy. 2019; doi:10.1016j.jphys.2019.08.004.

9. Atamaz FC, Durmaz B, Baydar M, Demircioglu OY, Iyiyapici A, Kuran B, Sendur OF. Comparison of the Efficacy of
Transcutaneous Electrical Nerve Stimulation, Interferential Currents, and Shortwave Diathermy in Knee Osteoarthritis: A Double-Blind, Randomized, Controlled, Multicenter Study. Archives of Physical Medicine and Rehabilitation. 2012; 93(5): 748-756.doi:10.1016/j.apmr.2011.11.037.

10. Jorge MSG, Zanin C, Knob B, and Wibelinger LM. Effects of Deep Heating to Treat Osteoarthritis Pain: Systematic Review. Revista Dor. 2017; 18 (1): doi:10.5935/1806-0013.20170016.

11. Wang $H$, Zhang $C$, Gao C, Zhu S, Yang L, Wei $Q$, and He C. Effects of Short-Wave Therapy in Patients with Knee Osteoarthritis: a Systematic Review and MetaAnalysis. (Abstract). Clinical Rehabilitation. 2016; 31(5):660 671. doi:10.1177/0269215516683000.

12. Cifu DX. Braddom's Physical Medicine and Rehabilitation E-Book. Elsevier Health Sciences. 2016.

13. Chruściak T. Subjective Evaluation of the Effectiveness of Whole-Body Cryotherapy in Patients with Osteoarthritis. Rheumatologia. 2016; 54(6):291-295. doi:10.5114/ reum.2016.64904.

14. Dantas LO, Breda CC, Mendes Silva Serrao PR, Serafim Jorge $A H$, and Salvini TF. Cryotherapy Short-Term Use Relieves Pain, Improves Function and Quality of Life in Individuals with Knee Osteoarthritis -Randomized Controlled Trial. (Abstract). Osteoarthritis and Cartilage. 2017; 25: S174. doi:10.1016/j.joca.2017.02.302.

15. Adegoke, Babatunde, and Gbeminiyi. Efficacy of Ice and Shortwave Diathermy in the Management of Osteoarthritis on the Knee-a Preliminary. African Journal of Biomedical Research. 2004; 7:59-63. doi: 10.4314/ajbr.v7i2.54069. 